\title{
Pengaruh Harga dan Kualitas Pelayanan terhadap Keputusan Pembelian CV Obor Pematangsiantar
}

\author{
Ambo Enre ${ }^{1}$ \\ Sekolah Tinggi Akuntansi dan Manajemen Indonesia \\ amboenre@gmail.com
}

Henri Abdiel Simbolon ${ }^{3}$

Politeknik Bisnis Indonesia

henrysimbolon2015@gmail.com

\author{
Debora Silvia Hutagalung ${ }^{2}$ \\ Sekolah Tinggi Akuntansi dan Manajemen Indonesia \\ deborahutagalung9@gmail.com \\ Marcella Theresia Ong ${ }^{4}$ \\ Sekolah Tinggi Akuntansi dan Manajemen Indonesia \\ marcella.ong@gmail.com
}

\begin{abstract}
The development of the business world that is rapidly improving resulted in increasingly fierce competition so that various ways are done by business people to maintain and develop competitive advantage against their competitors. One of the business that also got affected by the intense competition at the moment is the building materials business in CV. Obor Pematangsiantar. Fierce competition requires the owner or manager of the $C V$. Obor Pematangsiantar to create a strategy that is able to compete and has an advantage so that customers decide to buy CV. Obor Pematangsiantar's product. The purpose of this study was to determine the effect of price and quality of service on purchasing decisions on the $C V$. Obor Pematangsiantar both partially and simultaneously. The results showed that: (1) price has a positive effect on purchasing decisions, this is evidenced by the value of $t_{\text {count }}>t_{\text {table }}(11,669>2,026)$ with a significance value of 0,000 (sig $\leq 0.05)$, (2) quality of service has a positive effect on decisions purchases with $t_{\text {count }}>t_{\text {table }}(21,414>$ 2,026) with a significance value of 0,000 (sig $\leq 0.05$ ), (3) price and service quality have a positive effect on purchasing decisions, this is evidenced by the value of $F_{\text {count }}>F_{\text {table }}(441,681>3,25)$ with a significance value of 0,000 (sig $\leq 0.05$ ).
\end{abstract}

\section{Keywords: Price, Service Quality and Purchasing Decisions}

\section{PENDAHULUAN}

Perkembangan dunia bisnis yang semakin pesat mengakibatkan persaingan semakin ketat sehingga berbagai cara dilakukan para pelaku bisnis untuk menjaga dan mengembangkan keunggulan kompetitif dengan pesaingnya. Salah satu bisnis usaha yang juga merasakan ketatnya persaingan saat ini adalah bisnis bahan bangunan pada $\mathrm{CV}$. Obor Pematangsiantar. CV. Obor Pematangsiantar adalah salah satu usaha yang bergerak di bidang penjualan bahan-bahan bangunan, yang berlokasi di Jalan Diponegoro No. 06 Pematangsiantar. Bahan bangunan yang dijual di CV. Obor Pematangsiantar memiliki jenis, merek dan ukuran yang berbeda. Persaingan yang ketat menuntut pihak pemilik atau pengelola $\mathrm{CV}$. Obor Pematangsiantar untuk menciptakan strategi yang mampu bersaing dan memiliki keunggulan agar pelanggan memutuskan untuk membeli produk $\mathrm{CV}$. Obor Pematangsiantar dibanding dengan kompetitor lainnya.

Dalam prosesnya, keputusan pembelian merupakan tindakan yang dilakukan pelanggan untuk membeli suatu produk. Pada dasarnya, pengambilan keputusan pembelian setiap orang sama namun proses dalam pengambilan keputusan pembelian pasti berbeda-beda. Adapun proses keputusan pembelian pelanggan melalui lima tahapan yaitu pengenalan masalah, pencarian informasi, evaluasi alternatif, keputusan pembelian, dan evaluasi pasca pembelian. Pada CV. Obor Pematangsiantar sebelum memutuskan untuk membeli, biasanya pelanggan akan mengenali 
masalah yang dihadapi yaitu tujuan untuk membeli produk tersebut. Selanjutnya pelanggan akan mencari informasi mengenai kebutuhan yang diinginkan serta mencari keberadaan CV. Obor Pematangsiantar.

Selain itu pada dimensi evaluasi alternatif yaitu pilihan akan bahan bangunan yang ditawarkan oleh CV. Obor Pematangsiantar yang berbedabeda jenisnya sehingga pelanggan mempunyai banyak pilihan akan kebutuhan dan keinginannya. Lalu pada dimensi keputusan pembelian yaitu pelanggan menetapkan pilihannya membeli bahan bangunan sesuai dengan kebutuhannya. Pada dimensi perilaku setelah pembelian yaitu pelanggan yang kembali melakukan pembelian bahan bangunan yang ditawarkan oleh CV. Obor Pematangsiantar bahkan turut serta dalam melakukan penjualan bahan bangunan tersebut kepada masyarakat.

Salah satu fenomena keputusan pembelian pada CV. Obor Pematangsiantar adalah lokasi perusahaan yang kurang strategis bagi pelanggan yang letak usahanya jauh dari lokasi perusahaan. Dimana perlu adanya peningkatan pelayanan mengenai informasi produk yang ditawarkan perusahaan kepada pelanggan yang lokasi perusahaannya kurang strategis. Selanjutnya evaluasi pasca pembelian, pelanggan merasakan kepuasan secara finansial sehingga dilakukan pembelian secara berulang-ulang.

Salah satu faktor yang mempengaruhi keputusan pembelian adalah harga. Harga yang diberikan CV. Obor Pematangsiantar dapat diukur dalam tiga dimensi yaitu keterjangkauan harga, potongan harga dan cara pembayaran. Pada aspek keterjangkauan harga, dimana CV. Obor Pematangsiantar memberikan penawaran harga yang cukup tinggi kepada pelanggan, sehingga tidak jarang pelanggan melakukan perbandingan harga dengan penawaran yang diberikan CV. Obor Pematangsiantar dan memutuskan untuk membeli di tempat lain. Potongan harga yang diberikan oleh CV. Obor Pematangsiantar masih belum memuaskan pelanggan dikarenakan pelanggan harus membeli produk dalam jumlah banyak agar bisa memperoleh potongan harga. Sedangkan cara pembayaran yang ada pada CV. Obor Pematangsiantar hanya memiliki dua cara pembayaran yaitu tunai dan kredit saja, serta belum tersedianya layanan pembayaran melalui debet card atau internet banking.

Faktor lain yang mempengaruhi keputusan pembelian adalah kualitas pelayanan. Kualitas pelayanan pada CV. Obor Pematangsiantar dapat diukur dalam lima dimensi yaitu kehandalan, jaminan, bukti fisik, empati, dan daya tanggap. Implementasi kualitas pelayanan yang dilakukan oleh CV. Obor Pematangsiantar dapat dilihat pada dimensi kehandalan dimana karyawan $\mathrm{CV}$. Obor Pematangsiantar memberikan pelayanan sesuai dengan prosedur yang dijanjikan dengan menghindari kesalahan-kesalahan yang fatal. Kemudian pada dimensi jaminan dimana CV. Obor Pematangsiantar memberikan jaminan dalam hal keamanan bertransaksi maupun privasi pelanggan. Selain itu pada dimensi bukti fisik dimana CV. Obor Pematangsiantar menyediakan fasilitas ruangan yang nyaman bagi pelanggannya. Lalu dimensi empati dimana karyawan CV. Obor Pematangsiantar memiliki kemampuan komunikasi dan memahami kebutuhan khusus pelanggan, dan pada dimensi daya tanggap dimana karyawan CV. Obor Pematangsiantar memiliki kemampuan dalam menanggapi permintaan, keluhan maupun saran yang diberikan pelanggan.

Pada dimensi jaminan menurut pengamatan penulis kurang optimal, karena sering adanya produk rusak yang sudah diperbaiki tetapi masih mengalami kerusakan kembali dalam waktu yang singkat, sehingga terkadang pelanggan merasakan pelayanan yang diberikan oleh CV. Obor Pematangsiantar masih kurang optimal. Pada dimensi empati, yaitu kemampuan komunikasi karyawan yang masih kurang baik, dimana tidak jarang CV. Obor Pematangsiantar menerima komplain mengenai ketidaksesuaian produk yang diterima dengan apa yang sudah dibeli atau dibayarkan. Hal ini terjadi karena adanya kesalahan komunikasi antara pelanggan dengan karyawan yang bertugas. Selain itu, dimensi daya tanggap juga kurang optimal, hal 
ini dapat dilihat dari kurang tanggapnya bagian teknisi ketika pelanggan mengklaim produkproduk rusak yang masih dalam masa garansi.

\section{LANDASAN TEORITIS Manajemen Pemasaran}

Sebuah perusahaan akan menjadi sukses apabila di dalamnya terdapat manajemen pemasaran yang baik. Manajemen pemasaran pun menjadi pedoman dalam menjalankan kelangsungan hidup perusahaan sejak dimulainya proses produksi hingga barang sampai pada konsumen.

Pengertian manajemen pemasaran menurut Kotler dan Keller (2016:27) adalah Marketing management as the art and science of choosing target amrkets and getting, keeping, and growing customers throught creating, delivering and communicating superior customer value.

Sedangkan menurut Herry Achmad Buchary dan Djaslim Saladin (2013:10), "Manajemen pemasaran adalah analisis, perencanaan, penerapan dan pengendalian program yang dirancang untuk menciptakan, membangun dan mempertahankan pertukaran yang menguntungkan pasar sasaran dengan maksud untuk mencapai tujuan-tujuan organisasi."

Lalu pengertian lain yang dikemukakan oleh Ben M. Enis dalam Buchari Alma (2014:130) menyatakan bahwa manajemen pemasaran adalah proses untuk meningkatkan efisiensi dan efektivitas dari kegiatan pemasaran yang dilakukan oleh individu atau oleh perusahaan.

Danang Sunyoto mengemukakan bahwa manajemen pemasaran adalah fungsi bisnis yang mengidentifikasi kebutuhan dan keinginan konsumen yang harus dipuaskan oleh kegiatan manusia lain yang menghasilkan alat pemuas kebutuhan, yang berupa barang maupun jasa.

\section{Bauran Pemasaran (Marketing Mix)}

Bauran pemasaran (marketing mix) mempunyai peranan yang sangat dalam mempengaruhi pelanggan untuk membeli produk atau jasa yang ditawarkan dipasar, oleh karena itu bauran pemasaran (marketing mix) dikatakan sebagai suatu perangkat yang akan menunjukan tingkat keberhasilan pemasaran. Bauran pemasaran (marketing mix) sendiri meliputi kombinasi variabel-variabel yang saling berhubungan satu sama lainnya yang mencakup empat (4) hal pokok dan dapat dikontrol oleh perusahaan yang meliputi produk (product), harga (price), tempat (place) dan promosi (promotion).

Bauran pemasaran menurut Kotler dan Armstrong (2014:76) adalah the set of tactical marketing tools product, price, place and promotion that the firm blends to produce the response it wants in the target market. Sedangkan pengertian laìnnya dari Assauri (2013:75) bahwa bauran pemasaran adalah kombinasi variabel atau kegiatan yang merupakan inti dari sistem pemasaran, yaitu variabel yang dapat dikendalikan oleh perusahaan untuk mempengaruhi reaksi para pembeli atau konsumen. Lalu Ratih Hurriyati (2015:30) mengemukakan bauran pemasaran adalah sekumpulan alat pemasaran (marketing mix) yang dapat digunakan oleh perusahaan untuk mencapai tujuan pemasarannya dalam pasar sasaran.

Berdasarkan beberapa definisi tersebut peneliti sampai pada pemahaman bahwa bauran pemasaran (marketing mix) merupakan suatu alat pemasaran yang dijadikan strategi dalam kegiatan perusahaan guna mencapai tujuan perusahaan yang optimal. Dalam bauran pemasaran terdapat alat-alat pemasaran yang diklasifikasikan menjadi empat (4) kelompok yang luas yang disebut 4P pemasaran, Kotler dan Armstrong (2014:76) mengklasifikasikan sebagai berikut:

- Product : Product means the goods and services combination the company offers to the target market.

- 2. Price : Price is the amount of money customers must past to obtain the product.

- 3. Place : Place includes company activities that make the product available to target consumer. 
- Promotion : Promotion means activities that communicate the merits of the product and persuade target customers to buy it.

Bauran pemasaran $4 \mathrm{P}$ tersebut untuk produk barang dan untuk bauran pemasaran jasa diperluas, yaitu : orang (people), bukti fisik (physchal evidence) dan proses (process) sehingga menjadi 7 unsur (7P), menurut Fandy Tjiptono (2014:38)

- Orang (People) : Semua pelaku yang memainkan peranan dalam penyajian sehingga dapat mempengaruhi persepsi pelanggan.

- Fisik (Physical evidence) : Suatu hal yang secara nyata turut mempengaruhi keputusan konsumen untuk membeli dan menggunakan produk atau jasa yang ditawarkan.

- Proses (Process) : Semua Prosedur, mekanisme dan aliran aktifitas digunakan untuk menyampaikan pesan.

Berdasarkan penjelasan tersebut mengenai bauran pemasaran, maka dapat disimpulkan bahwa bauran pemasaran memiliki elemen elemen yang sangat berpengaruh dalam penjualan karena elemen tersebut dapat mempengaruhi minat konsumen dalam melakukan keputusan pembelian.

\section{Keputusan Pembelian}

Keputusan pembelian Menurut Buchari Alma (2014:96), mengemukakan bahwa keputusan pembelian adalah suatu keputusan konsumen yang dipengaruhi oleh ekonomi keuangan, teknologi, politik, budaya, produk, harga, lokasi, promosi, physical evidence, people dan process, sehingga membentuk suatu sikap pada konsumen untuk mengolah segala informasi dan mengambil ke simpulan berupa response yang muncul produk apa yang akan dibeli.

Keputusan pembelian didefinisikan oleh Kotler \& Keller (2016:192): "In the evaluation stage, the consumer forms preferences among the brands in the choice and may also form an intention to buy the most preferred brand" Sementara itu keputusan konsumen untuk melakukan pembelian suatu produk meliputi 6 sub keputusan, menurut
Kotler dan Keller yang dialih bahasakan oleh Benyamin Molan (2013:183) sebagai berikut :

1. Product Choice (Pilihan Produk)

Konsumen dapat mengambil keputusan untuk membeli sebuah produk atau menggunakan uangnya untuk tujuan yang lain. Dalam hal ini perusahaan harus memusatkan perhatiannya kepada orangorang yang berminat membeli sebuah produk serta alternatif yang mereka pertimbangkan.

2. Brand Choice (Pilihan Merek)

Konsumen harus mengambil keputusan tentang merek mana yang akan dibeli. Setiap merek memiliki perbedaanperbedaan tersendiri. Dalam hal ini perusahaan harus mengetahui bagaimana konsumen memilih sebuah merek yang terpercaya.

3. Dealer Choice (Pilihan Tempat Penyalur) Konsumen harus mengambil keputusan tentang penyalur mana yang akan dikunjungi. Setiap konsumen berbedabeda dalam hal menentukan penyalur bisa dikarenakan faktor lokasi yang dekat, harga yang murah, persediaan barang yang lengkap, kenyamanan berbelanja, keluasan tempat dan lain sebagainya.

4. Purchase Amount (Jumlah Pembelian Kuantitas)

Konsumen dapat mengambil keputusan tentang seberapa banyak produk yang akan dibelinya pada suatu saat. Pembelian yang dilakukan mungkin lebih dari satu jenis produk. Dalam hal ini perusahaan harus mempersiapkan banyaknya produk sesuai dengan keinginan yang berbeda-beda dari para pembeli.

5. Purchase Timing (Waktu Pembelian)

Keputusan konsumen dalam pemilihan waktu pembelian bisa berbeda-beda, misalnya : ada yang membeli setiap hari, satu minggu sekali, dua minggu sekali, tiga minggu sekali atau sebulan sekali dan lainlain.

6. Payment Method (Metode Pembayaran) Konsumen dapat mengambil keputusan tentang metode pembayaran yang akan dilakukan dalam pengambilan keputusan konsumen menggunakan produk atau jasa. 
Saat ini keputusan pembelian dipengaruhi oleh tidak hanya aspek budaya, lingkungan, dan keluarga, keputusan pembelian juga dipengaruhi oleh teknologi yang digunakan dalam transaksi pembelian sehingga memudahkan konsumen untuk melakukan transaksi baik di dalam maupun di luar rumah.

\section{METODOLOGI PENELITIAN}

Desain penelitian yang digunakan adalah:

\section{Penelitian Kepustakaan (Library Research)}

Teknik pengumpulan data yang dilakukan dengan menggunakan data sekunder yang berwujud teori dan lain-lain. Dalam metode ini, penelitian dilakukan langsung dengan cara mencari informasi melalui internet, catatan kuliah dan referensi lainnya yang berhubungan dengan kualitas pelayanan, harga, dan keputusan pembelian pelanggan.

\section{Penelitian Lapangan (Field Research)}

Penelitian yang dilakukan dengan cara melakukan peninjauan langsung ke lokasi penelitian. Penelitian ini dilakukan dengan cara mendapatkan data langsung dari wawancara terhadap pimpinan, karyawan dan pelanggan CV Obor Pematangsiantar.

Adapun jenis data yang digunakan dalam penelitian ini adalah:

\section{Data Kualitatif}

Data kualitatif, yaitu data yang diperlukan untuk menganalisa masalah dalam penelitian berupa data-data, tidak dinyatakan dalam angka. Data kualitatif yang digunakan dalam penelitian ini yaitu sejarah perusahaan, struktur organisasi, tugas dan tanggung jawab karyawan yang terdapat pada CV Obor Pematangsiantar.

\section{Data Kuantitatif}

Data kuantitatif, yaitu data penelitian yang berupa angka-angka atau data kualitatif yang diangkakan (scoring). Yang digolongkan sebagai data kuantitatif dalam penelitian ini berupa data yang diperoleh dari pengisian kuesioner tentang harga, kualitas pelayanan, dan keputusan pembelian.

Adapun sumber data yang digunakan dalam penelitian ini adalah:

\section{Data Primer}

Data primer adalah data yang diperoleh langsung dari perusahaan. Data primer diperoleh dari hasil wawancara dan penyebaran kuesioner kepada pelanggan CV Obor Pematangsiantar.

\section{Data Sekunder}

Data sekunder adalah data yang diperoleh dari pihak lain, yaitu informasi mengenai data-data terkait harga dan kualitas pelayanan terhadap keputusan pembelian. Sumber data sekunder adalah bukti-bukti tulisan serta dokumentasi.

\section{HASIL DAN PEMBAHASAN}

Berikut diuraikan produk yang dihasilkan oleh CV Obor Pematangsiantar adalah sebagai berikut:

\begin{tabular}{|l|l|l|}
\hline No. & Nama Produk & Keterangan \\
\hline 1 & Semen Padang & Isi $50 \mathrm{~kg}$ dan $40 \mathrm{~kg}$ \\
\hline 2 & Semen Holcim & Isi $40 \mathrm{~kg}$ \\
\hline 3 & Shower & Isi $1 \mathrm{set}$ \\
\hline 4 & Cat Paragon & Isi $25 \mathrm{~kg}, 5 \mathrm{~kg}$, dan $1 \mathrm{~kg}$ \\
\hline 5 & $\begin{array}{l}\text { Cat Paragon } \\
\text { Premium }\end{array}$ & $\begin{array}{l}\text { Isi } 28 \mathrm{~kg}, 3,5 \mathrm{~kg} \text {, dan } 1 \\
\mathrm{~kg}\end{array}$ \\
\hline 6 & Cat Durashield & $\begin{array}{l}\text { Isi } 28 \mathrm{~kg}, 3,5 \mathrm{~kg}, \text { dan } 1 \\
\mathrm{~kg}\end{array}$ \\
\hline 7 & $\begin{array}{l}\text { Cat Kayu dan } \\
\text { Besi Polibest }\end{array}$ & Isi $1 \mathrm{~kg}$ \\
\hline 8 & $\begin{array}{l}\text { Cat Nippon Paint } \\
\text { Isi } 28 \mathrm{~kg}, 3,5 \mathrm{~kg}, \text { dan } 1 \\
\mathrm{~kg}\end{array}$ \\
\hline 9 & Cat Vinilex & Isi $25 \mathrm{~kg}, 5 \mathrm{~kg}$, dan $1 \mathrm{~kg}$ \\
\hline 10 & $\begin{array}{l}\text { Cat Genteng } \\
\text { Semua Merek }\end{array}$ & Isi $4 \mathrm{~kg}$ \\
\hline 11 & $\begin{array}{l}\text { Cat Jotun } \\
\text { Isi } 28 \mathrm{~kg}, 3,5 \mathrm{~kg}, \text { dan } 1 \\
\mathrm{~kg}\end{array}$ \\
\hline 12 & $\begin{array}{l}\text { Cat Kayu dan } \\
\text { Besi Jotun }\end{array}$ & Isi $1 \mathrm{~kg}$ \\
\hline 13 & Cat Dulux & Isi $28 \mathrm{~kg}$, dan $3,5 \mathrm{~kg}$ \\
\hline 14 & $\begin{array}{l}\text { Cat Kayu dan } \\
\text { Besi Dulux }\end{array}$ & Isi $1 \mathrm{~kg}$ \\
\hline 15 & Cat Dana Paint & Isi $28 \mathrm{~kg}, 5 \mathrm{~kg}$, dan $1 \mathrm{~kg}$ \\
\hline 16 & $\begin{array}{l}\text { Cat Kayu dan } \\
\text { Besi Dana Paint }\end{array}$ & Isi $1 \mathrm{~kg}$ \\
\hline 17 & Granit $60 / 60$ & Isi $4 \mathrm{keping}$ \\
\hline
\end{tabular}




\begin{tabular}{|l|l|l|}
\hline 18 & Keramik 50/50 & Isi 5 keping \\
\hline 19 & Keramik 40/40 & Isi 8 keping \\
\hline 20 & Keramik 30/30 & Isi 11 keping \\
\hline 21 & Keramik 25/20 & Isi 20 keping \\
\hline 22 & Keramik 20/20 & Isi 25 keping \\
\hline 23 & Pipa Rucika & Isi 1 kotak \\
\hline 24 & Seng & Isi 11 paret dan 9 paret \\
\hline 25 & Paku & Isi 1 kotak \\
\hline
\end{tabular}

(kualitas pelayanan) terendah (minimum) adalah 45 dan nilai X2 (kualitas pelayanan) tertinggi (maximum) adalah 75. Rata-rata (mean) nilai dari 40 responden untuk X2 (kualitas pelayanan) adalah 53,25 dengan standar deviasi sebesar 5,917. Dan nilai $Y$ (keputusan pembelian) terendah (minimum) adalah 40 dan nilai $\mathrm{Y}$ (keputusan pembelian) tertinggi (maximum) adalah 75 . Rata-rata

Dari tabel 4.1 di atas, dapat diketahu bahwa nama produk semen padang yang berada di CV Obor Pematangsiantar dengan isi $50 \mathrm{~kg}$ dan $40 \mathrm{~kg}$, produk semen holcin dengan isi $40 \mathrm{~kg}$ yang sesuai dengan kebutuhan pelanggan. Produk shower dengan isi 1 set, produk cat dengan merek paragon, vinilex dan dana paint mempunyai isi $25 \mathrm{~kg}, 5 \mathrm{~kg}$, dan $1 \mathrm{~kg}$ serta produk cat paragon premium, durashield, nippon paint, jotun, dan dulux mempunyai isi $28 \mathrm{~kg}, 3,5 \mathrm{~kg}$, dan $1 \mathrm{~kg}$ yang sesuai dengan keinginan pelanggan. Produk cat kayu dan besi dengan merek polibest, jotun, dulux dan dana paint mempunyai isi $1 \mathrm{~kg}$. Produk cat genteng dengan semua merek mempunyai isi $4 \mathrm{~kg}$. Produk granit dengan ukuran 60/60 mempunyai isi 4 keping, keramik dengan ukuran 50/50, 40/40, 30/30, 25/20, dan 20/20 masing-masing mempunyai isi 5 keping, 8 keping, 11 keping, 20 keping, 25 keping tergantung ukuran yang disesuaikan dengan kebutuhan pelanggan. Kemudian produk pipa rucika mempunyai isi 1 kotak, produk seng dengan isi 11 paret dan 9 paret perlembarnya dan produk paku dengan isi 1 kotak.

Adapun hasil deskripsi responden dalam penelitian ini adalah sebagai berikut:

\begin{tabular}{|l|r|r|r|r|r|}
\multicolumn{7}{|c|}{ Descriptive Statistics } \\
\hline & N & Minimum & Maximum & Mean & Std. Deviation \\
\hline Harga & 40 & 32 & 45 & 37.63 & 3.379 \\
Kualitas Pelayanan & 40 & 45 & 75 & 53.25 & 5.917 \\
Keputusan Pembelian & 40 & 40 & 75 & 50.18 & 6.931 \\
Unstandardized Residual & 40 & -1.69254 & 2.65460 & .0000000 & 1.38978608 \\
Valid N (listwise) & 40 & & & & \\
\hline
\end{tabular}

Berdasarkan hasil deskripsi responden pada tabel di atas menunjukkan jumlah responden (N) ada 40 orang. Dari 40 responden ini, nilai X1 (harga) terendah (minimum) adalah 32 dan nilai X1 (harga) tertinggi (maximum) adalah 45. Rata-rata (mean) nilai dari 40 responden untuk X1 (harga) adalah 37,63 dengan standar deviasi sebesar 3,379. Sedangkan nilai X2 (mean) nilai dari 40 responden untuk $\mathrm{Y}$ (keputusan pembelian) adalah 50,18 dengan standar deviasi sebesar 6,931.

\section{Uji Validitas}

Teknik untuk mengukur validitas kuesioner adalah dengan menghitung korelasi antar data pada masing-masing pernyataan dengan skor total. Item instrumen dianggap valid jika lebih besar dari 0,3 atau bisa juga membandingkannya dengan rkritis. Jika rhitung > rkritis maka valid. Adapun hasil uji validitas dalam penelitian ini dapat dilihat pada tabel berikut:

\begin{tabular}{|c|c|c|c|c|c|}
\hline $\begin{array}{c}\text { Variab } \\
\text { el }\end{array}$ & Dimensi & $\begin{array}{l}\text { Butir } \\
\text { Instru } \\
\text { men }\end{array}$ & $\begin{array}{c}\mathrm{r}_{\text {hitu }} \\
\mathrm{ng}\end{array}$ & $\begin{array}{c}\mathrm{r}_{\text {kri }} \\
\text { tis }\end{array}$ & $\begin{array}{c}\text { Ketera } \\
\text { ngan }\end{array}$ \\
\hline \multirow{9}{*}{$\begin{array}{l}\text { Harga } \\
\left(\mathrm{X}_{1}\right)\end{array}$} & \multirow{3}{*}{$\begin{array}{c}\text { Keterjangk } \\
\text { auan } \\
\text { Harga }\end{array}$} & $\mathrm{X} 1.1$ & $\begin{array}{l}0,7 \\
44\end{array}$ & $\begin{array}{l}0, \\
3\end{array}$ & Valid \\
\hline & & $\mathrm{X} 1.2$ & $\begin{array}{l}0,5 \\
92\end{array}$ & $\begin{array}{l}0, \\
3\end{array}$ & Valid \\
\hline & & $\mathrm{X} 1.3$ & $\begin{array}{l}0,6 \\
43\end{array}$ & $\begin{array}{l}0, \\
3\end{array}$ & Valid \\
\hline & \multirow{3}{*}{$\begin{array}{c}\text { Potongan } \\
\text { Harga }\end{array}$} & $\mathrm{X} 1.4$ & $\begin{array}{l}0,7 \\
72\end{array}$ & $\begin{array}{l}0, \\
3\end{array}$ & Valid \\
\hline & & $\mathrm{X} 1.5$ & $\begin{array}{l}0,6 \\
23\end{array}$ & $\begin{array}{l}0, \\
3\end{array}$ & Valid \\
\hline & & $\mathrm{X} 1.6$ & $\begin{array}{l}0,5 \\
56\end{array}$ & $\begin{array}{l}0, \\
3\end{array}$ & Valid \\
\hline & \multirow{3}{*}{$\begin{array}{c}\text { Cara } \\
\text { Pembayara } \\
\text { n }\end{array}$} & $\mathrm{X} 1.7$ & $\begin{array}{l}0,4 \\
45\end{array}$ & $\begin{array}{l}0, \\
3\end{array}$ & Valid \\
\hline & & $\mathrm{X} 1.8$ & $\begin{array}{l}0,6 \\
38\end{array}$ & $\begin{array}{l}0, \\
3\end{array}$ & Valid \\
\hline & & X1.9 & $\begin{array}{l}0,6 \\
56 \\
\end{array}$ & $\begin{array}{l}0, \\
3\end{array}$ & Valid \\
\hline \multirow{6}{*}{$\begin{array}{l}\text { Kualit } \\
\text { as } \\
\text { Pelaya } \\
\text { nan } \\
\left(\mathrm{X}_{2}\right)\end{array}$} & \multirow{3}{*}{$\begin{array}{c}\text { Kehandala } \\
\mathrm{n} \\
\text { (Reliability } \\
\text { ) }\end{array}$} & $\mathrm{X} 2.1$ & $\begin{array}{l}0,7 \\
30\end{array}$ & $\begin{array}{l}0, \\
3\end{array}$ & Valid \\
\hline & & $\mathrm{X} 2.2$ & $\begin{array}{l}0,6 \\
42\end{array}$ & $\begin{array}{l}0, \\
3\end{array}$ & Valid \\
\hline & & $\mathrm{X} 2.3$ & $\begin{array}{l}0,6 \\
04\end{array}$ & $\begin{array}{l}0, \\
3\end{array}$ & Valid \\
\hline & \multirow{3}{*}{$\begin{array}{c}\text { Jaminan } \\
\text { (Assurance } \\
\text { ) }\end{array}$} & $\mathrm{X} 2.4$ & $\begin{array}{l}0,4 \\
40\end{array}$ & $\begin{array}{l}0, \\
3\end{array}$ & Valid \\
\hline & & $\mathrm{X} 2.5$ & $\begin{array}{l}0,4 \\
80 \\
\end{array}$ & $\begin{array}{l}0, \\
3\end{array}$ & Valid \\
\hline & & $\mathrm{X} 2.6$ & $\begin{array}{l}0,5 \\
19\end{array}$ & $\begin{array}{l}0, \\
3\end{array}$ & Valid \\
\hline
\end{tabular}




\section{Owner \\ RISET \& JURNAL AKUNTANSI \\ Volume 4 Nomor 1 Februari 2020 \\ e -ISSN : 2548-9224 \\ RISET \& JURNAL AKUNTANSI \\ https://doi.org/10.33395/owner.v4i1.173 \\ p-ISSN : 2548-7507}

\begin{tabular}{|c|c|c|c|c|c|}
\hline & & $\mathrm{X} 2.7$ & 0,7 & 0 , & Valid \\
\hline & Bukti Fisik & $\mathrm{X} 2.8$ & 0,4 & 0 , & Valid \\
\hline & (Tangible) & & 98 & 3 & \\
\hline & & $\mathrm{X} 2.9$ & $\begin{array}{l}0,5 \\
53\end{array}$ & $\begin{array}{l}0, \\
3\end{array}$ & Valid \\
\hline & & $\mathrm{X} 2.10$ & 0,6 & 0 , & Valid \\
\hline & Empati & $\mathrm{X} 2.11$ & 0,7 & 0 , & Valid \\
\hline & & $\mathrm{X} 2.12$ & 0,4 & 0 , & Valid \\
\hline & & & 76 & 3 & \\
\hline & Daya & X2.13 & $\begin{array}{l}0,6 \\
42\end{array}$ & $\begin{array}{l}0, \\
3\end{array}$ & Valid \\
\hline & & $\mathrm{X} 2.14$ & 0,4 & 0 , & Valid \\
\hline & eness) & $\mathrm{X} 2.15$ & 0,5 & 0 , & Valid \\
\hline & & Y.1 & 0,5 & 0 , & Valid \\
\hline & Pengenalan & Y.2 & 0,7 & 0 , & Valid \\
\hline & & & 61 & 3 & \\
\hline & & Y.3 & $\begin{array}{c}0,5 \\
09\end{array}$ & $\begin{array}{l}0, \\
3\end{array}$ & Valid \\
\hline & & Y.4 & $\begin{array}{c}0,6 \\
03\end{array}$ & $\begin{array}{l}0, \\
3\end{array}$ & Valid \\
\hline & $\begin{array}{l}\text { Pencarian } \\
\text { Informasi }\end{array}$ & Y.5 & $\begin{array}{l}0,7 \\
09\end{array}$ & $\begin{array}{l}0, \\
3\end{array}$ & Valid \\
\hline & & Y.6 & $\begin{array}{l}0,6 \\
50\end{array}$ & $\begin{array}{l}0, \\
3\end{array}$ & Valid \\
\hline Keput & & Y.7 & $\begin{array}{l}0,5 \\
53\end{array}$ & $\begin{array}{l}0, \\
3\end{array}$ & Valid \\
\hline $\begin{array}{l}\text { usan } \\
\text { Pembe }\end{array}$ & $\begin{array}{c}\text { Evaluasi } \\
\text { Alternatif }\end{array}$ & Y.8 & $\begin{array}{l}0,7 \\
63\end{array}$ & $\begin{array}{l}0, \\
3\end{array}$ & Valid \\
\hline (Y) & & Y.9 & $\begin{array}{l}0,6 \\
31\end{array}$ & $\begin{array}{l}0, \\
3\end{array}$ & Valid \\
\hline & & Y.10 & $\begin{array}{l}0,6 \\
29\end{array}$ & $\begin{array}{l}0, \\
3\end{array}$ & Valid \\
\hline & $\begin{array}{l}\text { Keputusan } \\
\text { Pembelian }\end{array}$ & Y.11 & $\begin{array}{l}0,7 \\
89\end{array}$ & $\begin{array}{l}0, \\
3\end{array}$ & Valid \\
\hline & & Y.12 & $\begin{array}{l}0,4 \\
45\end{array}$ & $\begin{array}{l}0, \\
3\end{array}$ & Valid \\
\hline & & Y.13 & $\begin{array}{l}0,6 \\
82\end{array}$ & $\begin{array}{l}0, \\
3\end{array}$ & Valid \\
\hline & $\begin{array}{l}\text { Evaluasi } \\
\text { Pasca }\end{array}$ & Y.14 & $\begin{array}{l}0,5 \\
45\end{array}$ & $\begin{array}{l}0, \\
3\end{array}$ & Valid \\
\hline & 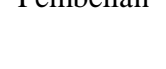 & Y.15 & $\begin{array}{l}0,7 \\
95\end{array}$ & $\begin{array}{l}0, \\
3\end{array}$ & Valid \\
\hline
\end{tabular}

\section{Uji Reliabilitas}

Uji reliabilitas adalah metode pengujian yang digunakan untuk menetapkan apakah instrumen yang dalam hal ini kuesioner dapat digunakan lebih dari satu kali, paling tidak oleh responden yang sama akan menghasilkan data yang konsisten. reliabilitas instrumen mencirikan tingkat konsistensi. Nilai koefisien reliabilitas dikatakan reliabel jika nilai
Cronbach's Alpha if Item Deleted $>$ dari nilai Cronbach's Alpha sebesar 0,70. Adapun hasil uji reliabilitas dalam penelitian ini dapat dilihat dalam tabel berikut:

\begin{tabular}{|c|c|c|c|c|c|}
\hline $\begin{array}{l}\text { Vari } \\
\text { abel }\end{array}$ & Dimensi & $\begin{array}{c}\text { Butir } \\
\text { Instru } \\
\text { men }\end{array}$ & $\begin{array}{c}\text { Cronba } \\
\text { ch's } \\
\text { Alpha } \\
\text { if Item } \\
\text { Delete } \\
\quad d\end{array}$ & $\begin{array}{c}\text { Cron } \\
\text { bach } \\
\text { 's } \\
\text { Alph } \\
\text { a }\end{array}$ & $\begin{array}{c}\text { Keterang } \\
\text { an }\end{array}$ \\
\hline \multirow{9}{*}{$\begin{array}{c}\text { Harg } \\
\text { a } \\
\left(\mathrm{X}_{1}\right)\end{array}$} & \multirow{3}{*}{$\begin{array}{c}\text { Keterjang } \\
\text { kauan } \\
\text { Harga }\end{array}$} & X1.1 & 0,765 & 0,70 & Reliabel \\
\hline & & $\mathrm{X} 1.2$ & 0,788 & 0,70 & Reliabel \\
\hline & & $\mathrm{X} 1.3$ & 0,781 & 0,70 & Reliabel \\
\hline & \multirow{3}{*}{$\begin{array}{c}\text { Potongan } \\
\text { Harga }\end{array}$} & X1.4 & 0,761 & 0,70 & Reliabel \\
\hline & & $\mathrm{X} 1.5$ & 0,787 & 0,70 & Reliabel \\
\hline & & X1.6 & 0,801 & 0,70 & Reliabel \\
\hline & \multirow{3}{*}{$\begin{array}{c}\text { Cara } \\
\text { Pembaya } \\
\text { ran }\end{array}$} & $\mathrm{X} 1.7$ & 0,810 & 0,70 & Reliabel \\
\hline & & $\mathrm{X} 1.8$ & 0,781 & 0,70 & Reliabel \\
\hline & & X1.9 & 0,779 & 0,70 & Reliabel \\
\hline \multirow{15}{*}{$\begin{array}{c}\text { Kual } \\
\text { itas } \\
\text { Pela } \\
\text { yana } \\
n \\
\left(\mathrm{X}_{2}\right)\end{array}$} & \multirow{3}{*}{$\begin{array}{c}\text { Kehandal } \\
\text { an } \\
\text { (Reliabili } \\
\text { ty) }\end{array}$} & $\mathrm{X} 2.1$ & 0,837 & 0,70 & Reliabel \\
\hline & & $\mathrm{X} 2.2$ & 0,842 & 0,70 & Reliabel \\
\hline & & $\mathrm{X} 2.3$ & 0,845 & 0,70 & Reliabel \\
\hline & \multirow{3}{*}{$\begin{array}{c}\text { Jaminan } \\
\text { (Assuran } \\
\text { ce) }\end{array}$} & $\mathrm{X} 2.4$ & 0,856 & 0,70 & Reliabel \\
\hline & & $\mathrm{X} 2.5$ & 0,851 & 0,70 & Reliabel \\
\hline & & $\mathrm{X} 2.6$ & 0,849 & 0,70 & Reliabel \\
\hline & \multirow{3}{*}{$\begin{array}{c}\text { Bukti } \\
\text { Fisik } \\
\text { (Tangible } \\
\text { ) }\end{array}$} & $\mathrm{X} 2.7$ & 0,837 & 0,70 & Reliabel \\
\hline & & $\mathrm{X} 2.8$ & 0,852 & 0,70 & Reliabel \\
\hline & & X2.9 & 0,848 & 0,70 & Reliabel \\
\hline & \multirow{3}{*}{$\begin{array}{c}\text { Empati } \\
\text { (Empathy } \\
\text { ) }\end{array}$} & $\mathrm{X} 2.10$ & 0,843 & 0,70 & Reliabel \\
\hline & & $\mathrm{X} 2.11$ & 0,839 & 0,70 & Reliabel \\
\hline & & $\mathrm{X} 2.12$ & 0,854 & 0,70 & Reliabel \\
\hline & \multirow{3}{*}{$\begin{array}{c}\text { Daya } \\
\text { Tanggap } \\
\text { (Responsi } \\
\text { veness) }\end{array}$} & $\mathrm{X} 2.13$ & 0,842 & 0,70 & Reliabel \\
\hline & & $\mathrm{X} 2.14$ & 0,851 & 0,70 & Reliabel \\
\hline & & $\mathrm{X} 2.15$ & 0,849 & 0,70 & Reliabel \\
\hline \multirow{15}{*}{$\begin{array}{c}\text { Kep } \\
\text { utusa } \\
\text { n } \\
\text { Pem } \\
\text { belia } \\
\text { n (Y) }\end{array}$} & \multirow{3}{*}{$\begin{array}{c}\text { Pengenal } \\
\text { an } \\
\text { Masalah }\end{array}$} & Y.1 & 0,893 & 0,70 & Reliabel \\
\hline & & Y.2 & 0,884 & 0,70 & Reliabel \\
\hline & & Y.3 & 0,895 & 0,70 & Reliabel \\
\hline & \multirow{3}{*}{$\begin{array}{l}\text { Pencarian } \\
\text { Informasi }\end{array}$} & Y.4 & 0,894 & 0,70 & Reliabel \\
\hline & & Y.5 & 0,886 & 0,70 & Reliabel \\
\hline & & Y.6 & 0,889 & 0,70 & Reliabel \\
\hline & \multirow{3}{*}{$\begin{array}{l}\text { Evaluasi } \\
\text { Alternatif }\end{array}$} & Y.7 & 0,893 & 0,70 & Reliabel \\
\hline & & Y.8 & 0,884 & 0,70 & Reliabel \\
\hline & & Y.9 & 0,890 & 0,70 & Reliabel \\
\hline & \multirow{3}{*}{$\begin{array}{c}\text { Keputusa } \\
n \\
\text { Pembelia } \\
n\end{array}$} & Y.10 & 0,890 & 0,70 & Reliabel \\
\hline & & Y.11 & 0,882 & 0,70 & Reliabel \\
\hline & & Y.12 & 0,898 & 0,70 & Reliabel \\
\hline & \multirow{3}{*}{$\begin{array}{c}\text { Evaluasi } \\
\text { Pasca } \\
\text { Pembelia } \\
\text { n }\end{array}$} & Y.13 & 0,888 & 0,70 & Reliabel \\
\hline & & Y.14 & 0,893 & 0,70 & Reliabel \\
\hline & & Y.15 & 0,883 & 0,70 & Reliabel \\
\hline
\end{tabular}

\section{Uji Normalitas}

Uji normalitas dilakukan untuk memeriksa apakah populasi berdistribusi normal atau tidak. Berikut ini merupakan tabel One-Sample Kolmogorov-Smirnov: 


\begin{tabular}{|c|c|c|}
\hline \multicolumn{3}{|c|}{ One-Sample Kolmogorov-Smirnov Test } \\
\hline & & $\begin{array}{l}\text { Unstandardiz } \\
\text { ed Residual }\end{array}$ \\
\hline N & & 40 \\
\hline Normal Parameters ${ }^{a, b}$ & Mean & .0000000 \\
\hline & Std. Deviation & 1.38978608 \\
\hline Most Extreme Differences & Absolute & .121 \\
\hline & Positive & .121 \\
\hline & Negative & -.112 \\
\hline Test Statistic & & .121 \\
\hline Asymp. Sig. (2-tailed) & & $.140^{\circ}$ \\
\hline
\end{tabular}

Berdasarkan tabel diatas, hasil uji normalitas One-Sample Kolmogorov-Smirnov Test di atas dapat dilihat nilai Asymp. Sig (2-tailed) pada Unstandardized Residual sebesar 0,140 lebih besar dari $\alpha 0,05$. Dengan demikian, dapat dinyatakan bahwa distribusi data dari masingmasing data variabel berdistribusi normal.

\section{Analisis Pengujian Hipotesis \\ Regresi Linier Berganda}

Regresi linier berganda dilakukan untuk menganalisa pengaruh variabel X1 (harga) dan variabel $\mathrm{X} 2$ (kualitas pelayanan) terhadap variabel Y (keputusan pembelian) pada CV Obor Pematangsiantar. hasil analisis regresi linier berganda dibawah ini:

\begin{tabular}{|c|c|c|c|c|c|c|}
\hline \multicolumn{7}{|c|}{ Coefficients $^{\mathrm{a}}$} \\
\hline \multirow[b]{2}{*}{ Model } & & \multicolumn{2}{|c|}{ Unstandardized Coefficients } & \multirow{2}{*}{$\begin{array}{c}\begin{array}{c}\text { Standardized } \\
\text { Coefficients }\end{array} \\
\text { Beta } \\
\end{array}$} & \multirow[b]{2}{*}{$t$} & \multirow[b]{2}{*}{ Sig. } \\
\hline & & $\mathrm{B}$ & Std. Error & & & \\
\hline \multirow[t]{3}{*}{1} & (Constant) & -28.673 & 2.836 & & -10.110 & .000 \\
\hline & Harga & .844 & .072 & .411 & 11.669 & .000 \\
\hline & Kualitas Pelayanan & .884 & .041 & .755 & 21.414 & .000 \\
\hline
\end{tabular}

Berdasarkan hasil pengolahan data pada tabel di atas, diperoleh model persamaan regresi sebagai berikut: $\mathrm{Y}=-28.673+0,844 \mathrm{X} 1+$ $0,884 \mathrm{X} 2$, artinya ada pengaruh yang positif antara harga (X1) dan kualitas pelayanan (X2) terhadap keputusan pembelian (Y) pada CV Obor Pematangsiantar.

\section{Analisis Koefisien Korelasi dan Koefisien Determinasi}

Untuk mengetahui seberapa besar hubungan antara variabel bebas yaitu harga dan kualitas pelayanan terhadap variabel terikat yaitu keputusan pembelian, maka diperlukan koefisien korelasi. Sedangkan koefisien determinasi bertujuan untuk mengetahui besarnya kontribusi variabel bebas terhadap variabel terikat.

Model Summary
\begin{tabular}{|l|c|c|c|c|}
\hline Model & R & R Square & $\begin{array}{c}\text { Adjusted R } \\
\text { Square }\end{array}$ & $\begin{array}{c}\text { Std. Error of } \\
\text { the Estimate }\end{array}$ \\
\hline 1 & $.980^{\text {a }}$ & .960 & .958 & 1.427 \\
\hline
\end{tabular}
a. Predictors: (Constant), Kualitas Pelayanan, Harga
b. Dependent Variable: Keputusan Pembelian

Berdasarkan hasil pengolahan data pada tabel di atas, diperoleh nilai $R=0,980$, yang artinya terdapat hubungan yang sangat kuat dan positif antara harga dan kualitas pelayanan terhadap keputusan pembelian pada CV Obor Pematangsiantar. Kemudian diperoleh nilai koefisien determinasi $(\mathrm{R}$ Square $)=0,960$ artinya tinggi rendahnya keputusan pembelian (Y) sebesar 96,0\% dapat dipengaruhi oleh faktor harga (X1) dan kualitas pelayanan (X2), sedangkan sisanya 4,0\% dipengaruhi oleh faktor lain seperti promosi, lokasi dan lain sebagainya yang tidak dibahas dalam penelitian ini.

\section{Uji Parsial (Uji t)}

Pengujian ini dilakukan secara parsial yaitu dilakukan untuk menentukan diterima atau ditolaknya hipotesis, pengujian hipotesis dilakukan untuk menguji apakah variabel harga dan kualitas pelayanan yang diuji berpengaruh terhadap keputusan pembelian. Jika thitung > ttabel atau signifikasi $\leq 0,05$, maka $\mathrm{H} 0$ ditolak

\begin{tabular}{|c|c|c|c|c|c|c|}
\hline \multirow[b]{2}{*}{ Mod } & & \multicolumn{2}{|c|}{ Unstandardized Coefficients } & \multirow{2}{*}{$\begin{array}{c}\text { Standardized } \\
\text { Coefficients } \\
\text { Beta }\end{array}$} & \multirow[b]{2}{*}{$t$} & \multirow[b]{2}{*}{ Sig. } \\
\hline & & $\mathrm{B}$ & Std. Error & & & \\
\hline \multirow[t]{3}{*}{1} & (Constant) & -28.673 & 2.836 & & -10.110 & .000 \\
\hline & Harga & .844 & .072 & .411 & 11.669 & .000 \\
\hline & Kualitas Pelayanan & .884 & .041 & .755 & 21.414 & .000 \\
\hline
\end{tabular}

Berdasarkan hasil pengolahan data pada tabel di atas, diperoleh nilai thitung pada variabel X1 (harga) sebesar 11,669 > ttabel dengan $\mathrm{df}=\mathrm{n}-$ $\mathrm{k}-1(40-2-1=37)$ sebesar 2,026 atau dengan taraf signifikan $0,000 \leq \alpha 0,05$, maka $\mathrm{H} 0$ ditolak, artinya harga berpengaruh positif dan signifikan terhadap keputusan pembelian pada CV Obor Pematangsiantar. Kemudian nilai thitung pada variabel X2 (kualitas pelayanan) sebesar 21,414 > ttabel dengan $\mathrm{df}=$ $\mathrm{n}-\mathrm{k}-1(40-2-1=37)$ sebesar 2,026 atau dengan taraf signifikan $0,000 \leq \alpha 0,05$, maka H0 ditolak, artinya kualitas pelayanan berpengaruh positif dan signifikan terhadap 
keputusan pembelian pada CV Obor Pematangsiantar.

\section{Uji Simutan (Uji F)}

Pengujian ini dilakukan secara simultan yaitu dilakukan untuk menentukan diterima atau ditolaknya hipotesis, pengujian hipotesis dilakukan untuk menguji apakah variabel harga dan kualitas pelayanan yang diuji berpengaruh terhadap keputusan pembelian. Jika Fhitung > Ftabel atau signifikasi $\leq 0,05$, maka H0 ditolak.

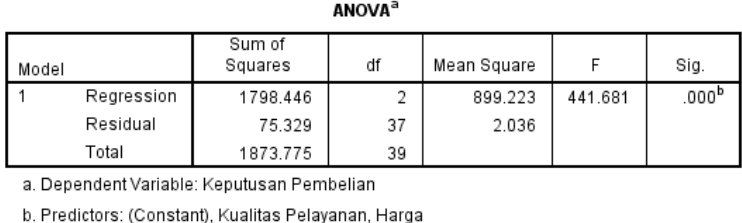

Berdasarkan hasil pengolahan data pada tabel di atas, diperoleh nilai Fhitung sebesar 441,681 $>$ Ftabel dengan $(0,05 ; 2$ vs 37$)$ sebesar 3,25 atau dengan taraf siginifikan $0,000 \leq \alpha 0,05$ maka H0 ditolak, artinya harga dan kualitas pelayanan berpengaruh positif dan signifikan terhadap keputusan pembelian pada CV Obor Pematangsiantar

\section{KESIMPULAN}

Dari hasil pengolahan data yang telah dilakukan, maka penulis menarik kesimpulan sebagai berikut:

1. Hasil uji validitas diketahui bahwa nilai rhitung dari semua instrumen lebih besar daripada rkritis maka dapat disimpulkan bahwa semua instrumen dari variabel dalam penelitian ini adalah valid.

2. Hasil uji reliabilitas diketahui bahwa semua instrumen Cronbach's Alpha if Item Deleted lebih besar dari 0,70. Hal ini berarti instrumen dalam penelitian ini adalah reliabel.

3. Hasil uji normalitas dengan metode OneSample Kolmogorov-Smirnov Test diperoleh nilai Asymp. Sig (2-tailed) pada Unstandardized Residual sebesar 0,140 lebih besar dari $\alpha 0,05$. Dengan demikian, dapat dinyatakan bahwa distribusi data dari masing-masing data variabel berdistribusi normal.

4. Hasil uji regresi linier berganda diperoleh model persamaan regresi sebagai berikut: $\mathrm{Y}=-28.673+0,844 \mathrm{X} 1+0,884 \mathrm{X} 2$, artinya ada pengaruh yang positif antara harga (X1) dan kualitas pelayanan (X2) terhadap keputusan pembelian (Y) pada CV Obor Pematangsiantar.

5. Hasil uji korelasi diperoleh nilai $\mathrm{R}=0,980$, yang artinya terdapat hubungan yang sangat kuat dan positif antara harga dan kualitas pelayanan terhadap keputusan pembelian pada CV Obor Pematangsiantar. Kemudian diperoleh nilai koefisien determinasi ( $\mathrm{R}$ Square) $=$ 0,960 artinya tinggi rendahnya keputusan pembelian (Y) sebesar 96,0\% dapat dipengaruhi oleh faktor harga (X1) dan kualitas pelayanan (X2), sedangkan sisanya $4,0 \%$ dipengaruhi oleh faktor lain seperti promosi, lokasi dan lain sebagainya.

6. Hasil uji hipotesis secara parsial (uji t) diperoleh nilai thitung pada variabel X1 (harga) sebesar 11,669 > ttabel dengan $\mathrm{df}$ $=\mathrm{n}-\mathrm{k}-1(40-2-1=37)$ sebesar 2,026 atau dengan taraf signifikan $0,000 \leq \alpha 0,05$, maka H0 ditolak, artinya harga berpengaruh positif dan signifikan terhadap keputusan pembelian pada CV Obor Pematangsiantar. Kemudian nilai thitung pada variabel X2 (kualitas pelayanan) sebesar 21,414 > ttabel dengan $\mathrm{df}=\mathrm{n}-\mathrm{k}-1(40-2-1=37)$ sebesar 2,026 atau dengan taraf signifikan $0,000 \leq \alpha 0,05$, maka H0 ditolak, artinya kualitas pelayanan berpengaruh positif dan signifikan terhadap keputusan pembelian pada CV Obor Pematangsiantar.

7. Hasil uji hipotesis secara simultan (uji F) diperoleh nilai Fhitung sebesar 441,681 > Ftabel dengan $(0,05 ; 2$ vs 37$)$ sebesar 3,25 atau dengan taraf siginifikan $0,000 \leq \alpha 0,05$ maka $\mathrm{H} 0$ ditolak, artinya harga dan kualitas pelayanan berpengaruh positif dan signifikan terhadap keputusan pembelian pada CV Obor Pematangsiantar.

\section{REFERENSI}

Alma, Buchari. 2014 .Manajemen Pemasaran dan Pemasaran Jasa.

Bandung: Alfabeta 
Assauri, Sofjan. 2013. Manajemen Pemasaran. Jakarta: Rajawali Pers

Aziz, Anton Mulyono dan Maya Irjayanti. 2014. Manajemen. Bandung: Mardika Group

Buchary, Herry Achmad dan Djaslim Saladin.2013. Manajemen pemasaran (Ringkasan praktis, teori, aplikasi \& tanya jawab). Bandung: Lindakarya

Fahmi, Irham.2014. Manajemen: teori, kasus, dan solusi.Bandung: Alfabeta

Ghozali, Imam.2016.Aplikasi Analisis Multivariate Dengan Program SPSS.Semarang: Universitas Diponegoro

Griffin, Ricky W.2013.Manajemen Jilid 2.Alih bahasa: Gina Gania.Jakarta: Erlangga

Handoko, Hani.2014.Manajemen Edisi 2. Yogyakarta: BPFE Yogyakarta

Hasan, Ali.2013.Marketing dan Kasus-Kasus Pilihan.Yogyakarta: CAPS (Center For Academic Publishing Service)

Hasibuan, Malayu S.P.2016.Manajemen Sumber Daya Manusia Edisi Revisi.Jakarta: PT Bumi Aksara

Hurriyati, Ratih.2015.Bauran Pemasaran dan Loyalita Konsumen.Bandung: Alfabeta
Kotler, Philip dan Gary Armstrong.2013.Prinsip-prinsip Pemasaran, Edisi ke-12.Jakarta: Erlangga

Kotler, Philip dan Gary Armstrong.2014.Principles of Marketing 15th Edition. New Jersey: Pearson Prectice Hall, Inc

Kotler, Philip dan Kevin Lane Keller.2013.Manajemen Pemasaran, Jilid 2, Edisi 13.Erlangga
Kotler, Philip dan Kevin Lane Keller.2016.Marketing Management 15th Edition. New Jersey: Pearson Prectice Hall, Inc

Lupiyoadi, Rambat.2013.Manajemen Pemasaran Jasa Berbasis Kompetensi (Edisi 3).Jakarta: Salemba Empat.

Nasution, M. N.2015.Manajemen Mutu Terpadu.Bogor: Ghalia Indonesia

Pasolong, Herbani.2011.Teori Administrasi Publik. Bandung: Alfabeta

Peter, J Paul dan Jerry C. Olson.2013.Perilaku Konsumen dan Strategi Pemasaran Edisi kesembilan Jilid 1.Terjemahan oleh Diah Tantri Dwiandani.Jakarta: Erlangga

[20] Ramli, Samsul.2013.Bacaan Wajib Para Praktisi Pengadaan Barang/Jasa Pemerintah.Jakarta: Visi Media

Sanusi, Abdurrahman. 2015. Manajemen Strategi Pemasaran.Bandung: CV Pustaka Setia

Sugiyono. 2017. Metode Penelitian Kuantitatif, Kualitatif, dan R\&D. Bandung : Alfabeta, CV

Sulastiyono,

Agus.2011.Manajemen

Penyelenggaraan Hotel: Manajemen Hotel. Bandung: Alfabeta

Sunyoto, Danang.2015.Manajemen dan Pengembangan Sumber Daya Manusia (Cetakan Pertama).Yogyakarta: CAPS (Center for Academic Publishing Service).

Suparyanto, Rosad. 2015.Manajemen Pemasaran.Bogor: In Media

Surjadi.2012.P engembangan Kinerja Pelayanan Publik. Bandung: Refika Aditama 
Tjiptono, Fandy.2014.Pemasaran Jasa (Prinsip, Penerapan, Penelitian).Yogyakarta: Andi

Tjiptono, Fandy dan Gregorius Chandra.2016.Service, Quality \& Satisfaction.Yogyakarta: Andi

Yamit, Zulian. 2010. Manajemen Kualitas Produk \& Jasa.Yogyakarta: Ekonisia 